\title{
A UTILIZAÇÃO DA APRENDIZAGEM BASEADA EM PROBLEMAS EM CURSOS DE GRADUAÇÃO DE CIÊNCIAS CONTÁBEIS ${ }^{1}$
}

\section{THE USE OF PROBLEM-BASED LEARNING IN UNDERGRADUATE CLASSES OF ACCOUNTING SCIENCES}

\section{EL USO DEL APRENDIZAJE BASADO EN PROBLEMAS EN CLASES DE PREGRADO DE CIENCIAS CONTABLES}

Natália Garcia de Oliveira, Mestre em Ciências Contábeis pela Universidade Federal de Minas Gerais (UFMG). Endereço Profissional: Universidade Federal de Alfenas (UNIFAL), Campus Varginha. Av. Celina Ferreira Otoni, n. 4.000, Padre Vitor, Varginha - MG. CEP 37.048-395. Homepage: www.unifal-mg.edu.br/. E-mail: ng.consultoriacontabil@gmail.com.

Márcia Athayde Moreira, Doutora em Controladoria e Contabilidade pela Universidade de São Paulo. Endereço Profissional: Universidade da Amazônia. Av. Alcindo Cacela, 287, Umarizal, Belém, PA - Brasil, CEP: 66.065-205. Telefone: (091) 40083018. Homepage: http://www.unama.br. E-mail: athayde.marcia@gmail.com.

\section{RESUMO}

O principal objetivo deste artigo consistiu em avaliar em docentes dos cursos de Ciências Contábeis de Instituições de Ensino Superior - IES do estado de Minas Gerais, o nível de aderência das práticas de ensino de disciplinas da contabilidade ao Problem Based Learning PBL. O PBL vai além das didáticas convencionais de ensino, trata-se de uma metodologia pautada em problemas da vida real, que estimula o pensar crítico, o trabalho em equipe e o desenvolvimento de habilidades para a resolução de problemas. Para atender ao objetivo proposto, foi construído um questionário baseando na estrutura apresentada pela Samford University (2000) contendo 29 assertivas. O questionário foi encaminhado para 46 instituições de ensino do estado de Minas Gerais, listadas conforme o ranking do ENAD 2012 e retornou 36 questionários válidos. Como resultado final, alcançou-se uma média de 7,02 pontos, o que é considerado Nível Médio de aderência das práticas de ensino ao PBL. Com o que os resultados parecem de certa forma satisfatórios. Concluiu-se que o ensino da contabilidade já possui algumas características do PBL, necessitando se consolidar e sistematizar nas IES pesquisadas, sendo que as principais deficiências são visualizadas na forma como os conteúdos são transmitidos, onde se percebe que os docentes ainda elaboram e ministram suas aulas com base em modelos tradicionais de ensino, priorizando a estrutura de palestras, e muitas vezes não permitindo que os alunos participem ativamente do processo avaliativo.

Palavras-Chave: Aprendizagem Baseada em Problemas; Ensino e Contabilidade.

\section{ABSTRACT}

The main objective of this article was to evaluate the level of adherence of the teaching practices in accounting disciplines with Problem Based Learning (PBL) methodology during classes of Accounting Sciences in under graduation institutions located in the state of Minas

\footnotetext{
${ }^{1}$ Artigo submetido em 27/10/2016, revisado em 25/04/2017, aceito em 01/08/2017 e divulgado em 15/12/2017 pelo Editor João Carlos Hipólito Bernardes do Nascimento, após double blind review.

GєCont, v. 4, n. 2, Floriano-PI, Jul-Dez. 2017.
} 
Gerais. The PBL goes beyond conventional teaching, it is a methodology based on real-life problems, which stimulates critical thinking, teamwork and development of problem solving skills. To achieve this proposed objective, a questionnaire was constructed based on the structure presented by Samford University (2000) containing 29 questions. The questionnaire was sent to 46 educational institutions in the state of Minas Gerais, listed according to the ENAD 2012 ranking and 36 were questionnaires were returned. As a final result, an average of 7.02 points was reached, which is considered as the Average Level of adherence of teaching practices to the PBL. Thus the results seem somewhat satisfactory, it was concluded that the method of teaching in accounting already has some characteristics of the PBL, needing just to be consolidated and systematized in the institutions researched. Being that the main deficiencies are visualized in the way the contents are transmitted, where it is perceived that the professors still elaborate and presenting their classes based on traditional teaching models, prioritizing the structure of lectures, and often not allowing students to participate actively in the evaluation process.

Key Words: Problem-Based Learning; Teaching and Accounting.

\section{RESUMEN}

El objetivo principal de este artículo fue evaluar el nivel de adherencia de las prácticas docentes en disciplinas contables con la metodología de Aprendizaje Basado en Problemas (PBL) durante las clases de Ciencias Contables en las instituciones de graduación ubicadas en el estado de Minas Gerais. El PBL va más allá de la enseñanza convencional, es una metodología basada en problemas de la vida real, que estimula el pensamiento crítico, el trabajo en equipo y el desarrollo de habilidades para resolver problemas. Para lograr este objetivo propuesto, se elaboró un cuestionario basado en la estructura presentada por la Universidad de Samford (2000) que contiene 29 preguntas. El cuestionario fue enviado a 46 instituciones educativas en el estado de Minas Gerais, enumeradas de acuerdo con el ranking ENAD 2012 y 36 fueron cuestionarios devueltos. Como resultado final, se alcanzó un promedio de 7.02 puntos, que se considera como el nivel promedio de adherencia de las prácticas de enseñanza al PBL. Por lo tanto, los resultados parecen algo satisfactorios, se concluyó que el método de enseñanza en contabilidad ya tiene algunas características del PBL, necesitando solamente para ser consolidado y sistematizado en las instituciones investigadas. Siendo que las principales deficiencias se visualizan en la forma en que se transmiten los contenidos, donde se percibe que los profesores aún elaboran y presentan sus clases en base a modelos de enseñanza tradicionales, priorizan la estructura de las clases y muchas veces no permiten que los estudiantes participen activamente en el proceso de evaluación.

Palabras clave: Aprendizaje basado en problemas; Enseñanza y Contabilidad.

\section{INTRODUÇÃO}

acesso à educação nos últimos anos foi facilitado pelos incentivos
governamentais, tais como, o Programa Universidade Para Todos - PROUNI e
o Fundo de Financiamento Estudantil - FIES. Os cursos universitários passaram a fazer parte do cotidiano de muitos brasileiros, e a oferta no mercado educacional cresceu significativamente em uma década, seja na modalidade presencial ou à distância (BRASIL, 2014).

Em uma sociedade que vive grandes mudanças culturais e tecnológicas, muitas vezes encontram-se questionamentos sobre qual a melhor metodologia de ensino, capaz de desenvolver habilidades necessárias em um profissional para obter reconhecimento pelo mercado. No contex to educacional, existem muitas questões e poucas soluções.

GєCont, v. 4, n. 2, Floriano-PI, Jul-Dez. 2017. 
Certamente, para que se evolua em termos de metodologias de ensino, paradigmas precisam ser quebrados, salas de aula pautadas por metodologias tradicionais de ensino precisam ser repensadas. De acordo com Masetto (2014), ainda é muito comum encontrar um perfil tradicional do professor, que é expert em determinada área, um profissional com práticas de êxito do mercado e vem para a sala de aula apenas para comunicar isso ao aluno.

Essa questão é transversal e afeta também as ciências contábeis, provocando especificamente nessa área um paradoxo interessante, a aplicação de metodologias tradicionais de ensino em estudantes que adentram em uma profissão dinâmica, que se aprimora e pressiona a cada dia seus profissionais pela necessidade de mudança, seja em quesitos técnicos, seja em suas relações com o mundo.

Conforme Marion e Santos (2014) espera-se que o contador esteja em grande evolução, pois além de uma série de atributos indispensáveis da profissão contábil, não é mais possível (sobre)viver com postura de escriturador.

Marion e Santos (2014) destacam ainda a ausência de comunicação entre as instituições de ensino e o mercado de trabalho. Existe uma grande necessidade de atualização nas grades curriculares, no intuito de atualizar as metodologias aplicadas em sala de aula, além da necessidade de inserir novos conteúdos, que permitam aos alunos adequação às novas tendências do mercado de trabalho (MARION; SANTOS, 2014).

Para ser um agente de mudanças como dele se espera, o profissional da área contábil deve demonstrar diversas habilidades, tais como: líder, comunicador, culto, ético, avaliador, consultor, entre outros, sendo de grande importância a habilidade de pesquisador, no intuído de atualizar os conhecimentos adquiridos. Neste contexto, a utilização das técnicas do Problem Based Learning - PBL pode ser essencial no desenvolvimento de tais habilidades.

Ribeiro (2005, p. 32) ao argumentar sobre o PBL “[...] trata-se de um método de instrução caracterizado pelo uso de problemas da vida real que visa estimular o pensamento crítico e o desenvolvimento de habilidades na solução de problemas, assim como a aprendizagem de conceitos fundamentais da área em estudo".

Sendo assim, a introdução de métodos criativos e inovadores no processo de aprendizado deverá ser um fator de motivação para a mudança de comportamento e melhoria na formação destes profissionais. A integração de alunos e docentes com visão crítica e participativa, são elementos primordiais. Dentre os métodos, este artigo abordará o PBL, uma metodologia crescente no processo de ensino-aprendizagem em todo o mundo.

Diante do exposto, este artigo pretende responder a seguinte questão: Qual é o nível de aderência das metodologias utilizadas para o ensino da contabilidade com a metodologia PBL em Cursos de Graduação em Ciências Contábeis? Sendo que o objetivo geral é o de avaliar, junto à docentes dos cursos de Ciências Contábeis de Instituições de Ensino Superior IES, o nível de aderência das práticas de ensino de disciplinas da contabilidade ao ProblemBased Learning - PBL.

Este trabalho justifica-se pela necessidade de novos elementos na relação ensino aprendizagem para formar profissionais capacitados a pensar e resolver problemas complexos da vida real.

\section{REFERENCIAL TEÓRICO}

\subsection{APRENDIZAGEM BASEADA EM PROBLEMAS: ORIGEM E CONCEITOS}

De acordo com Ribeiro (2008), o PBL originou-se na Escola de Medicina da Universidade McMaster no Canadá, no final dos anos 1960, sua implantação no contexto educacional surgiu em virtude da insatisfação do ensino em relação às práticas médicas, o volume de conhecimentos era tido como irrelevante. Estudantes deixavam o curso com muitos

GєCont, v. 4, n. 2, Floriano-PI, Jul-Dez. 2017. 
conceitos, porém dotados de poucas estratégias e comportamentos associados à aplicação de informação a um diagnóstico.

O PBL tem se modificado para se adaptar a outros contextos educacionais, podendo ser encontrado, inclusive no Brasil, embora o método tenha sido concebido para o ensino da medicina, seus princípios têm se mostrado adequados para implantação no ensino de outras áreas de conhecimento (RIBEIRO, 2008).

De acordo com Ribeiro (2008) o PBL não pode ser considerado uma metodologia recente, visto que a aprendizagem a partir de confrontos com problemas tem acontecido desde os primórdios. Sendo que no Brasil, é possível identificar alguns de seus elementos norteadores nas intenções dos fundadores da Universidade de São Paulo na década de 1930.

Mas de forma sistematizada e controlada, o uso do PBL, para Silva Filho (2010) os pioneiros a utilizarem no Brasil, foram os cursos de pós-graduação da Faculdade de Medicina de Marília, em São Paulo, e da Universidade Estadual de Londrina, no Paraná. Essas experiências foram referências para a transformação de vários cursos de medicina em várias universidades brasileiras. Schwartz et al. (2001) contribuíram afirmando que após sua difusão, a metodologia passou a ser utilizada em outros cursos das ciências da saúde, engenharia, arquitetura, negócios, direito, matemática, agricultura e outras disciplinas, e contribui para o aprendizado, trabalho em equipe e desenvolvimento interpessoal dos alunos. Schwartz et al. (2001) asseveram ainda que a crescente popularidade da metodologia decorre do aumento de interesse entre pesquisadores educacionais em estudar os seus efeitos. Muitos estudos têm olhado para o PBL a partir de uma série de perspectivas, para investigar uma ou mais questões. Conforme relacionado abaixo:

O desempenho em avaliações pelos alunos, que aprenderam utilizando PBL, em comparação com aqueles que aprenderam por métodos mais tradicionais.

Os comportamentos de estudo e processos de pensamentos que são promovidas pelo PBL

A satisfação dos estudantes com o currículo do PBL

A adequação da preparação de graduados por currículos de PBL.

A satisfação dos membros do corpo docente com o currículo do PBL (SCHWARTZ et al. 2001, p. 17).

O PBL carrega consigo um diferencial e tem sido tema de pesquisas nos EUA, Inglaterra, Canadá, Austrália, Holanda, Brasil, dentre outros países. Há uma busca por novas formas de ensino que tendem a se expandir a cada dia. Existem várias definições e interpretações para o PBL, entretanto, algumas faculdades e instituições adotam a definição de Barrows e Kelson (1993) como original. Esta definição foi extraída da Samford University nos EUA.

PBL é simultaneamente um currículo e um processo. O currículo é composto por problemas cuidadosamente selecionados e projetados que exigem do aluno a aquisição de conhecimento crítico, resolução de problemas de proficiência, estratégias de aprendizagem autodirigida, e habilidades para o trabalho em equipes. O processo reproduz a abordagem sistêmica comumente usada para resolver problemas ou enfrentar desafios que são encontrados na vida e carreira (Tradução Livre) (SAMFORD, 2014, sp.).

De forma resumida, Woods (2014, s/p.), contribui afirmando que o "PBL é qualquer ambiente de aprendizagem no qual o problema impulsiona o aprendizado. [...] O problema se coloca de modo que os alunos descobrem que eles precisam aprender novos conhecimentos para que possam resolvê-lo". Para Martins (2002, p. 128) "um problema é utilizado como estímulo à aquisição de conhecimento e compreensão de conceitos. Ele é o elemento central em um currículo de aprendizagem baseada em problema".

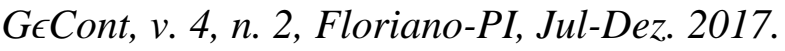


Duch (2014) define o PBL como um ambiente de aprendizagem no qual o problema é utilizado para iniciar, direcionar, motivar e focar a aprendizagem, diferenciando dos métodos convencionais que utilizam problemas de aplicação ao final da apresentação de um conceito ou conteúdo.

Conforme Schwartz et al. (2001), embora a finalidade do PBL seja voltada para o uso de problemas, a intenção é estimular a aprendizagem a partir da obtenção de informações e conceitos trazidos por estes problemas. Tem como objetivo ensinar tanto um método de abordagem quanto uma atitude para resolver tais problemas.

De acordo com Martins (2002), no PBL o estudante utiliza cada problema para desenvolver habilidades para soluciona-lo. Não é dada nenhuma informação previa ao aluno, este se torna o centro de todo o processo na construção da aprendizagem. Ao utilizar esta metodologia para o ensino, pretende-se atingir dois objetivos:

1) Utilizar um método que ajude os alunos a se tornarem proficientes num conjunto de competências (de trabalho, de cooperação, de colaboração, raciocínio, etc.) generalizáveis, que são relevantes durante a sua vida futura,

2) Criar condições favoráveis à aprendizagem ao longo da vida (MARTINS, 2002, P. 129).

Martins (2002, p. 35) ensina que a abordagem construtivista no ensino, "implica deixar de ver o aluno como um receptor de conhecimentos, não importando como os armazena em sua mente, e passar a considerá-lo um agente de uma construção que é a sua própria estrutura cognitiva".

Assim, de forma geral, o PBL busca, junto com outras metodologias educacionais com base construtivista, responder alguns dilemas colocados à educação profissional contemporânea que se depara com o aumento espetacular do volume de conhecimentos científicos e tecnológicos que devem ser ensinados aos alunos durante a graduação e seu ritmo acelerado de obsolescência (RIBEIRO, 2005).

\subsection{APRENDIZAGEM BASEADA EM PROBLEMAS: PRINCÍPIOS E MÉTODO PROPOSTO}

Embora o PBL possua mais de 30 anos de pesquisa e utilização bem-sucedida no mundo, a metodologia tem sido criticada por não possuir uma base científica. Nenhuma fundamentação teórica foi explicitada por seus idealizadores. Porém, os princípios que formam a base do PBL guardam muitas semelhanças com as teorias de Ausubel, Bruner, Dewey, Piaget, Rogers, entre outros (RIBEIRO, 2008; MARTINS; ESPEJO, 2015).

Nesse sentido, Ribeiro (2008) argumenta que a utilização de problemas como ponto de partida para a aprendizagem poderia ser atribuída a Dewey, que foi um defensor da importância do aprender em resposta e em interação com eventos da vida real. A maioria dos autores encontra fundamentação para o PBL na psicologia cognitiva. Afirmando que a aprendizagem é um processo de construção de novos conhecimentos, o PBL estaria pautado no pressuposto de que a aprendizagem é influenciada pela metacognição e fatores sociais (RIBEIRO, 2008).

Assim, os cinco princípios que norteiam o PBL foram expostos por Ribeiro (2005), sendo a Interação Social; Motivação Epistêmica; Interação com a Vida Real; Metacognição; Construção do Conhecimento. 
Figura 1: Princípios da aprendizagem que fundamentam o PBL

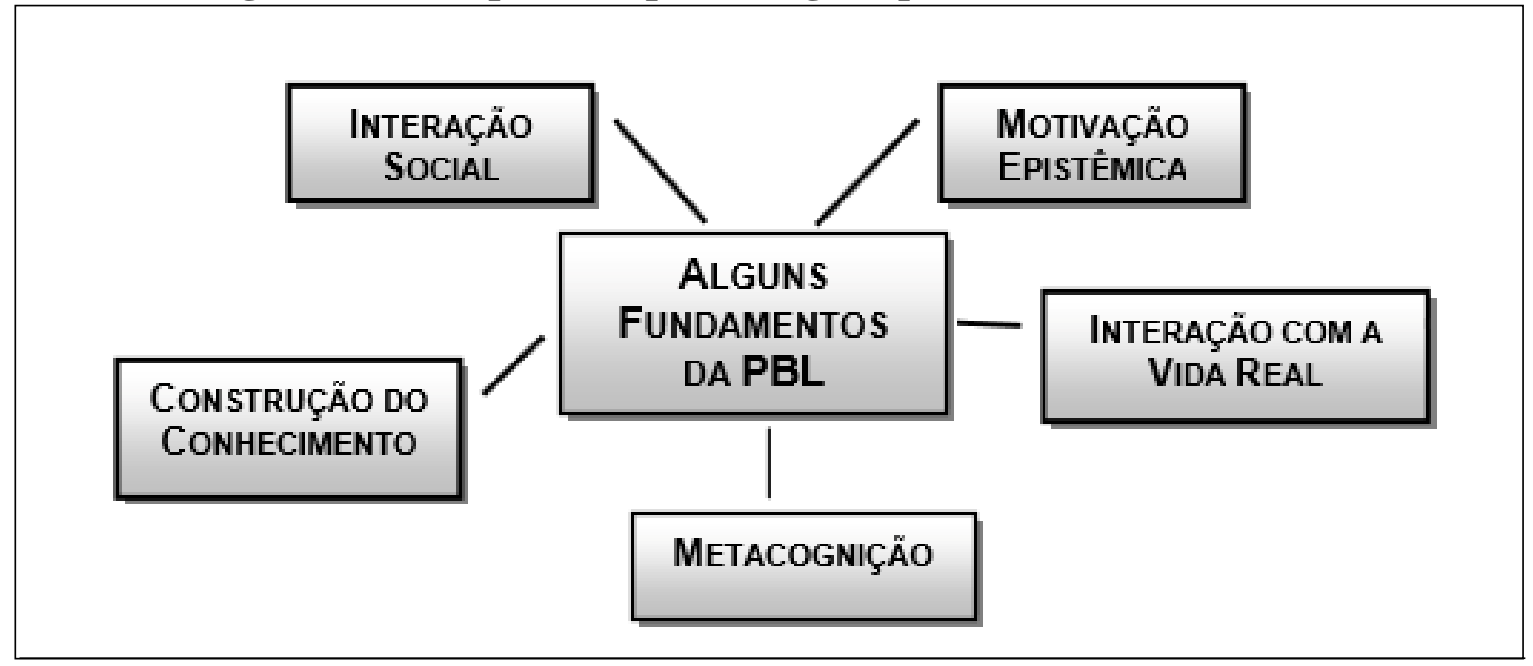

Fonte: Ribeiro (2005, p. 34).

Para Ribeiro (2005), a aprendizagem ocorre por meio da Interação Social quando há intermédio da cooperação, de informações e conceitos. A Motivação Epistêmica está relacionada em assumir responsabilidades pelo o andamento do próprio trabalho, o que desperta grande potencial de promoção da motivação intrínseca a aprendizagem. Ocorre principalmente nos casos em que os grupos possuem liberdade para se autogerir.

Na Metacognição, Wolfs (2000) trata-se da capacidade do indivíduo de deliberadamente controlar e planejar seus próprios processos. Para Ribeiro (2005), na Construção do Conhecimento, o docente irá atuar como orientador, co-aprendiz e facilitador. Os alunos serão responsáveis pela construção conjunta de conhecimentos. O autor também ressalta a importância de aprender a partir da interação com eventos da vida real.

Do ponto de vista operacional, se destaca o ensino por meio do trabalho em grupo e atividades que valorizem a convivência e a criatividade, buscando criar espaços para o trabalho cooperativo, colaborando para a aprendizagem mútua e completa, na qual o aluno apresenta se como um investigador reflexivo, competente, produtivo, autônomo, dinâmico e participativo (SOUZA; DOURADO, 2015).

De acordo com Woods (2000), no PBL, a avaliação dos alunos deve ser baseada em evidências multidimensionais, que somem situações estáticas e dinâmicas, pequenos e/ou também projetos longos, considerando contextos acadêmicos, sociais e pessoais, sob uma variedade de condições de desempenho, tendo pessoas diferentes como avaliadores.

\subsection{O PBL NOS CURSOS DE GRADUAÇÃO}

Para Duch, Groh e Allen (2001), a incorporação do PBL em cursos típicos de graduação, especialmente em universidades de pesquisa, é um desafio que vale a pena realizar, a fim de ajudar os alunos a desenvolverem habilidades de aprendizagem ao longo da vida que irá ajudálos a ter sucesso. Com base nesta afirmação é possível verificar a importância da introdução do PBL no ensino universitário.

Nesse sentido, e trazendo a discussão para o universo das ciências contábeis, Martins e Espejo $(2015$, p. 2) ressaltam que "[...] o PBL no ensino da contabilidade visa solucionar o impasse educacional criado pelas tecnologias de informação e de comunicação e pelos estudantes da Geração Y". As exigências legais, sociais e profissionais do contador, ao afetarem a gestão empresarial exigem que este profissional apresente competências que vão além do domínio do conhecimento técnico-científico, é preciso ter habilidades para solucionar 
problemas, exercer o pensamento crítico-reflexivo, estimular a criatividade para identificar os pontos fortes e fracos, ser adaptável às mudanças e ter autonomia para construir sua própria aprendizagem (SOARES; ARAÚJO, 2008).

De acordo com Martins (2013) o ensino em contabilidade deve trabalhar não apenas o conhecimento, mas também, habilidades e atitudes exigidas do futuro profissional para atuar com competência no mercado de trabalho.

Nesta perspectiva, entende-se que a competência é o conjunto de Conhecimentos, Habilidades e Atitudes (CHA) necessários ao futuro profissional para exercer as funções/atividades do contador gerencial em um determinado contexto empresarial. O primeiro elemento contempla os saberes teóricos e práticos, o segundo refere-se à capacidade do profissional de aplicar o conhecimento que possui e o terceiro está relacionado ao ato de querer fazer algo e a forma como é realizada tal tarefa. (MARTINS, 2013).

Em um trabalho realizado por Frezzatti et al. (2014) os autores tiveram como objetivo identificar as dificuldades presentes em parte do processo de avaliação de alunos envolvidos em curso Ciências Contábeis e Atuariais, ministrados a partir da ótica do PBL, em uma universidade pública brasileira. A experiência foi desenvolvida no último ano dos cursos, sendo a única disciplina da faculdade a utilizar esta abordagem.

Como resultado, Frezzatti et al. (2014) concluíram que pelo fato do PBL não ser uma iniciativa institucional e a primeira experiência desses alunos, percebeu-se que não foram todos os alunos que detinham, ao final da disciplina, o discernimento para elencar os elementos que os levaram a serem aprovados. Para os autores, a disciplina atingiu ao objetivo de integrar ensino, pesquisa e prática, sendo o PBL uma metodologia capaz de estimular o aluno a desenvolver a análise crítica necessária para ser um profissional mais preparado.

Outra aplicação bem sucedida do PBL no Brasil foi realizada por Athayde (2014), com a implantação da disciplina Contabilidade Empreendedora na Universidade Federal de Minas Gerais, a qual propunha, por meio do PBL a resolução de problemas empresariais complexos e reais por meio da aplicação da contabilidade e suas ferramentas, estimulando nos alunos do curso de ciências contábeis o desenvolvimento de características empreendedoras próprias, a fim de fomentar o desenvolvimento empresarial e a conscientização da responsabilidade socioambiental, em interações reais vivenciadas junto à empresários da região metropolitana de Belo Horizonte em períodos de três meses de convivência.

A literatura internacional também apresenta estudos do PBL voltados à contabilidade. Em trabalho realizado por Stanley e Stephen (2012) os autores tiveram como objetivo responder o seguinte questionamento: Aprendizagem Baseada em Problemas, a educação contábil precisa disto? Para alcançar a resposta, os autores realizaram uma pesquisa na Queensland University of Tecnology na Austrália.

Os autores que também são professores universitários, desenvolveram uma metodologia, denominada FIRDE (Fatos, Ideias, Pesquisa, Decisão, Execução), o FIRD foi aplicado em uma disciplina ao final do curso de Ciências Contábeis, para que os alunos pudessem obter contato com o processo da Aprendizagem Baseada em Problemas.

Após este período de disseminação do PBL no curso, os pesquisadores realizaram uma pesquisa com os alunos, tendo como intuito avaliar a qualidade do ensino a partir da introdução do PBL. O direcionamento foi para as seguintes habilidades: Questionamento; Trabalho em Equipe e Solução de Problemas. Os autores apresentaram as seguintes conclusões:

Em relação ao questionamento: sim, foi muito útil, mesmo que às vezes os alunos encontrassem dificuldades. As respostas revelaram que a partir do PBL foi eficaz o desenvolvimento dessa habilidade. Em relação ao trabalho em equipe: trabalho em equipe é muitas vezes difícil de gerir em um ambiente com muitos estudantes. No entanto, o PBL mostrou que a metodologia foi bem-sucedida. Em relação à solução de problemas: os alunos 
afirmaram que eles estavam agora, mais confortáveis para lidar com problemas não estruturados (STANLEY; STEPHEN, 2012).

Assim, dos estudos realizados considerando a adoção do PBL nos cursos de Ciências Contábeis, dentre as pesquisas internacionais, Johnstone e Biggs (1998); Breton (1999); Milne e McConneell (2001); James Hansen (2006); Wilkin e Collier (2009); Silva (2009); Sarrico e Santiago (2010, 2011a, 2011b); Manaf, Ishak e Hussin (2011). No Brasil, destacam-se Araújo (2006); Benjamim Junior \& Casa Nova (2012); Frezzatti \& Silva (2012); Athayde (2014); Martins, Espejo e Frezatti (2015).

Assim, observa-se que apesar do tempo, esforço e criatividade necessária para o desenvolvimento e implementação do PBL, recompensas significativas podem ser obtidas nos resultados de aprendizagem dos alunos. A partir dos conceitos, propostas e casos de sucesso da metodologia analisados, pode-se observar que o PBL promove uma formação que permite a integração entre a teoria e prática, promovendo o domínio de conhecimentos específicos e também de habilidades e atitudes profissionais e cidadãs (RIBEIRO, 2008). Schwartz et al. (2001) ressaltam que o PBL estimulou e desafiou professores, alunos e administradores de todo o mundo a refletir sobre a sua filosofia educacional e metodologias de ensino adotadas.

\section{METODOLOGIA DA PESQUISA}

Quanto ao objetivo, este estudo é classificado como descritivo, tem como intuito observar os fatos, registrá-los, analisá-los, classificá-los e interpretá-los, sem que haja a interferência do pesquisador (ANDRADE, 2002). Quanto aos procedimentos de pesquisa, é classificado como levantamento.

O instrumento de coleta de dados utilizado foi o questionário que possui a característica de atingir um maior número de pessoas simultaneamente a um custo menor, garantir o anonimato e obter várias respostas às mesmas perguntas, o que permite quantificar e comparar os resultados obtidos (DUARTE; FURTADO, 2002).

$\mathrm{O}$ meio utilizado para aplicação foi à internet. $\mathrm{O}$ questionário foi estruturado em duas partes, a primeira refere-se à qualificação dos respondentes, e segunda é composta por assertivas relacionadas a aplicação de metodologias que se assemelham ao PBL.

As assertivas foram desenvolvidas com base na estrutura utilizada por Ribeiro (2008, p. 48). O link contendo as assertivas foi encaminhado via e-mail, no decorrer dos meses de novembro e dezembro de 2014 aos coordenadores dos cursos de Ciências Contábeis de IES localizadas no estado de Minas Gerais. Foi solicitado a eles o repasse do link da pesquisa aos docentes que lecionam disciplinas relacionadas com a contabilidade.

A amostra foi composta por 46 IES, sendo 08 Públicas e 38 Privadas. A identificação das IES foi proposta a partir da Seleção Exame - Os melhores e piores cursos de Ciências Contábeis segundo o ENAD 2012. Publicado em outubro de 2013.

Para atender ao objetivo da pesquisa, foi solicitado aos professores que lecionam disciplinas relacionadas com a contabilidade que atribuíssem uma nota de 0 a 10 para cada assertiva, de forma que fosse capaz de expressar com fidedignidade o grau de utilização das práticas inerentes a metodologia do PBL em seu processo de ensino. Nesse ponto cabe destacar que os professores não foram avisados de que se tratava de um estudo sobre PBL, apenas solicitados a opinar sobre as práticas em sala de aula. A atribuição de nota 0 (zero) representando que a prática não era aplicada e 10 (dez) indicando total aplicação. Os resultados encontrados para as 17 assertivas, estão sintetizados em apêndice. Para as assertivas 01 e 02, devido à natureza dos questionamentos, houve a necessidade de reformular a pontuação, considerou-se que quanto maior a concordância, menor seria o score e a média obtida.

Dessa forma, optou-se por adotar uma escala com diferencial semântico, que se baseia na ideia de que o significado de um objeto detém particularidades difíceis de serem captadas e

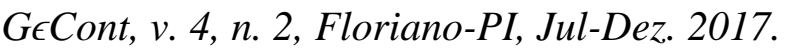


conhecidas de outra forma (OLIVEIRA, 2001). A escala consiste em uma série de termos extremos, que qualificam o objeto a respeito do qual se deseja a opinião do indivíduo, posicionados cada um num dos extremos (SAMPIERI et al., 2006). A pontuação foi definida conforme Tabela 1, considerando os níveis de aderência ao PBL.

Tabela 1: Critérios para avaliar o nível de aderência ao PBL

\begin{tabular}{l|c}
\hline \multicolumn{1}{c|}{ Categoria de Pontuação - Média } & Nível de aderência do PBL \\
\hline Menor que 5,00 pontos & Baixo \\
\hline Maior que 5,00 e Menor que 7,50 & Médio \\
\hline Maior que 7,50 & Alto \\
\hline
\end{tabular}

Fonte: Elaborado pelas autoras

Os resultados foram analisados de forma quantitativa, utilizando-se o software estatístico Minitab para a organização e tratamento estatístico dos dados.

\section{ANÁLISE DOS RESULTADOS}

Foram obtidas 36 respostas válidas para produzir o relatório da pesquisa, cuja qualificação dos respondentes é apresentada na Tabela 2.

Tabela 2: qualificação dos respondentes

\begin{tabular}{|c|c|c|c|}
\hline Identificação & Itens & Frequência & Percentual \\
\hline Gênero & $\begin{array}{l}\text { Masculino } \\
\text { Feminino }\end{array}$ & $\begin{array}{l}22 \\
14\end{array}$ & $\begin{array}{l}61,11 \% \\
38,89 \%\end{array}$ \\
\hline Idade & $\begin{array}{l}\text { Entre } 20 \text { e } 29 \text { anos } \\
\text { Entre } 30 \text { e } 39 \text { anos } \\
\text { Entre } 40 \text { e } 49 \text { anos } \\
\text { Acima de } 50 \text { anos }\end{array}$ & $\begin{array}{c}6 \\
14 \\
13 \\
3 \\
\end{array}$ & $\begin{array}{c}16,67 \% \\
38,89 \% \\
36,11 \% \\
8,33 \% \\
\end{array}$ \\
\hline Tipo de Instituição & $\begin{array}{l}\text { Centro Universitário } \\
\text { Faculdade } \\
\text { Universidade }\end{array}$ & $\begin{array}{c}4 \\
10 \\
22 \\
\end{array}$ & $\begin{array}{l}11,11 \% \\
27,78 \% \\
61,11 \% \\
\end{array}$ \\
\hline Natureza da Instituição & $\begin{array}{l}\text { Fundação de ensino } \\
\text { Privada } \\
\text { Publica }\end{array}$ & $\begin{array}{c}4 \\
16 \\
16 \\
\end{array}$ & $\begin{array}{l}11,12 \% \\
44,44 \% \\
44,44 \% \\
\end{array}$ \\
\hline Tempo de Experiência & $\begin{array}{l}\text { Até dois anos } \\
\text { De dois a cinco anos } \\
\text { De seis a dez anos } \\
\text { Mais de dez anos }\end{array}$ & $\begin{array}{c}7 \\
10 \\
8 \\
11\end{array}$ & $\begin{array}{l}19,44 \% \\
27,78 \% \\
22,22 \% \\
30,56 \% \\
\end{array}$ \\
\hline $\begin{array}{l}\text { Tempo de trabalho na } \\
\text { instituição }\end{array}$ & $\begin{array}{l}\text { Até dois anos } \\
\text { De dois a cinco anos } \\
\text { De seis a dez anos } \\
\text { Mais de dez anos }\end{array}$ & $\begin{array}{c}16 \\
6 \\
9 \\
5\end{array}$ & $\begin{array}{l}44,44 \% \\
16,67 \% \\
25,00 \% \\
13,89 \% \\
\end{array}$ \\
\hline Dedicação exclusiva & $\begin{array}{l}\text { Sim } \\
\text { Não }\end{array}$ & $\begin{array}{l}13 \\
23 \\
\end{array}$ & $\begin{array}{l}36,11 \% \\
63,89 \%\end{array}$ \\
\hline Formação Acadêmica & $\begin{array}{l}\text { Ciências Contábeis } \\
\text { Outros }\end{array}$ & $\begin{array}{c}31 \\
5\end{array}$ & $\begin{array}{l}86,11 \% \\
13,89 \%\end{array}$ \\
\hline Nível de Formação & $\begin{array}{l}\text { Especialização } \\
\text { Mestrado } \\
\text { Doutorado } \\
\end{array}$ & $\begin{array}{c}8 \\
22 \\
6 \\
\end{array}$ & $\begin{array}{l}22,22 \% \\
61,11 \% \\
16,67 \% \\
\end{array}$ \\
\hline Ranking ENAD & $\begin{array}{l}\text { Melhores } \\
\text { Piores }\end{array}$ & $\begin{array}{l}24 \\
12 \\
\end{array}$ & $\begin{array}{l}66,67 \% \\
33,33 \% \\
\end{array}$ \\
\hline
\end{tabular}

Fonte: Elaborada pelas autoras.

GєCont, v. 4, n. 2, Floriano-PI, Jul-Dez. 2017. 
Considerando os dados retornados, constatou-se que os docentes apresentam o seguinte perfil: a maior parte da amostra foi composta pelo gênero masculino com $61,11 \%$ dos respondentes, sendo que, a idade predominante foi entre 30 e 39 anos (38,89\%). Em relação ao tipo de instituição na qual lecionam, $61,11 \%$ atuam em universidades. Quanto a natureza institucional, 11,11\% estão alocados em fundação de ensino, 44,44\% em instituições públicas e $44,44 \%$ em instituições privadas.

O tempo de experiência que apresentou maior percentual foi acima de dez anos 30,56\%. Em relação à dedicação ao ensino, apenas $36,11 \%$ possuem dedicação exclusiva e $63,89 \%$ se dedicam também a outras atividades profissionais. Quanto a formação, $86,11 \%$ são contadores. Analisando o nível de formação, há predominância de mestres $61,11 \%$, seguido por especialistas $22,22 \%$ e por último, doutores representando apenas $16,67 \%$. A tabela 2 qualifica os respondentes, no que se observa uma diversidade importante para a análise subsequente acerca das metodologias de ensino aplicadas em sala de aula.

\subsection{UTILIZAÇÃO DO PBL NOS CURSOS DE CIÊNCIAS CONTÁBEIS}

Conforme já mencionado na metodologia, a segunda parte do questionário aplicado aos docentes dos cursos de Ciências Contábeis de Minas Gerais foi constituída por um grupo de assertivas às quais foram atribuídas uma pontuação de 0 a 10, indicando o grau de aplicação que melhor refletisse a adoção das práticas inerentes ao PBL no processo de ensino. A atribuição de nota 0 (zero) representando que a prática não era aplicada e 10 (dez) indicando total aplicação. Considerando 36 respondentes válidos, o escore máximo total é de 360 pontos, o qual corresponderia a uma média 10.

\subsection{REALIZAÇÃO DE ANÁLISE POR GRUPO}

A análise da Tabela 3 indica as médias entre as assertivas já divididas em três grupos, conforme classificado na metodologia da pesquisa:

Menor que 5,00 (Nível Baixo);

Maior que 5,00 e Menor que 7,50 (Nível Médio);

Maior que 7,50 (Nível Alto).

Os resultados indicaram que nove assertivas obtiveram respostas, na média, acima de 7,50 , seguido pelo grupo de seis assertivas que obtiveram médias maiores que 5,00 e menores que 7,50 e por último um grupo mais preocupante, composto de duas assertivas, com a média menor que 5,00 .

Percebe-se a partir da Tabela 3 que os escores atribuídos pelos respondentes foi diversificado, e a variável que obteve menor escore médio atingiu 2,86 (no processo avaliativo, atuo como único avaliador) e a que obteve maior escore apresentou 9,22 da pontuação máxima de 10 (sempre incentivo os alunos na busca pelo conhecimento e desenvolvimento de habilidades relevantes para a sua futura prática profissional).

Com os resultados apurados, foi possível verificar que nenhuma questão apresentou o escore máximo ou média 10 , sendo que, a maior média alcançada foi a concordância entre os docentes em relação ao incentivo aos alunos na busca pelo conhecimento e desenvolvimento de habilidades relevantes para a sua futura prática profissional.

O detalhamento dos resultados, por grupo, é apresentado na sequência. 


\subsubsection{Grupo 1: Nível Baixo}

Compuseram esse grupo duas assertivas. A primeira assertiva (No processo avaliativo, atuo como único avaliador). Foi obtido um escore de 103 pontos e média de 2,86, o que remete a percepção que, os alunos não participam do processo de avaliação conforme é previsto na metodologia do PBL, descrito por Woods (2000). Nesta questão é possível visualizar a predominância de didáticas tradicionais de ensino que conforme Samford (2000), nesta metodologia, a avaliação de desempenho escolar é somativa e o instrutor é o único avaliador.

A segunda assertiva (Os conteúdos nas disciplinas em que leciono, são conduzidos em formato de palestra). Foi obtido um escore de 154 pontos e média de 4,28, confirmando que estes profissionais não estão diversificando a sua forma de ensinar, utilizando metodologias em que o conteúdo é simplesmente transmitido aos alunos de forma convencional e pouco criativa, indo de encontro aos pressupostos do ensino no PBL, conforme articulam Souza e Dourado (2015), que destacam o trabalho em grupo e as atividades cooperativas como pontos-chave do ensino no PBL.

A média alcançada em conjunto foi de 4,27 pontos, o que é considerado um Baixo Nível de aderência ao PBL para estas assertivas, sendo predominantes as características inerentes as Metodologias Tradicionais de Ensino.

\subsubsection{Grupo 2: Nível Médio}

Seis assertivas compuseram esse grupo. A primeira assertiva (Dou abertura para que os alunos avaliem suas próprias contribuições, além de outros membros e do grupo como um todo). Foi obtido como resultado um escore de 204 pontos e média de 5,68, sendo assim, infere-se que os docentes, de modo geral prezam pela participação dos alunos em sala de aula. Essa situação é fundamental na metodologia, contribui para que os alunos se tornem proficientes em competências essenciais e relevantes para a vida futura, como assevera Martins (2002),

A segunda assertiva (Nas minhas aulas, os alunos se responsabilizam por sua própria aprendizagem e buscam a criação de parcerias entre colegas e professores). Foi obtido como resultado um escore de 223 pontos e média de 6,19, sendo assim, infere-se que há a construção conjunta do conhecimento entre alunos e docentes. Essa autonomia é fundamental, de acordo com Martins (2002), que ressalta que no PBL o estudante utiliza cada problema para desenvolver habilidades para soluciona-lo, e se torna o centro de todo o processo na construção da aprendizagem.

A terceira assertiva (A estrutura escolar na qual estou inserido (a) é flexível e oferece apoio aos docentes. Sou encorajado (a) a mudar o panorama instrucional e avaliativo mediante novos instrumentos de avaliação). Foi obtido como resultado um escore de 224 pontos e média de 6,22. Sendo que a estrutura escolar permite aos docentes, flexibilidade para a mudança do panorama institucional e existe incentivos a criação de novos instrumentos avaliativos. O que afasta o cenário predominante em metodologias tradicionais. Conforme Sanford (2002) em uma estrutura de ensino tradicional, os docentes tendem a trabalhar individualmente dentro das disciplinas.

A quarta assertiva (Busco desencorajar a resposta correta, única e ajudo os alunos a delinearem questões, equacionarem problemas, explorarem alternativas e tomarem decisões eficazes). Foi obtido um escore de 241 pontos e média de 6,69 pontos. O que indica que os docentes atuam para que os alunos sejam capazes de desenvolver habilidades relacionadas a construção de problemas e tomada de decisões, eixo principal do desenvolvimento no PBL, o qual preza pela habilidade para solucionar problemas, exercer o pensamento crítico-reflexivo, estimular a criatividade e ser adaptável (SOARES; ARAÚJO, 2008).

A quinta assertiva (Os alunos identificam, analisam e resolvem problemas utilizando conhecimentos prévios e experiências anteriores, ao invés de simplesmente relembrá-los). Foi

GєCont, v. 4, n. 2, Floriano-PI, Jul-Dez. 2017. 
obtido um score de 256 pontos e média de 7,11. Observa-se nesse quesito a autonomia para o aluno construir sua própria aprendizagem (SOARES; ARAÚJO, 2008), a qual não está vinculada a memorização de conceitos, mas entremeada por sua bagagem cultural, de valores e de conhecimentos anteriores, resgatados e valorizados em sala de aula.

Por fim, a sexta assertiva (Apresento o conteúdo utilizando problemas não estruturados que proporcionam o desenvolvimento de habilidades. Não incentivando a memorização de informações em um conteúdo específico). Ou seja, os alunos possuem espaço para utilizarem a criatividade no processo de aprendizado, não sendo necessário recorrer a métodos que incentive a memorização de conteúdos. O resultado obtido por esta questão apresentou um escore de 261 pontos e média de 7,25, Com base nesta análise, introduzem-se os ensinamentos Martins (2002), a autora apresenta a importância da construção do aprendizado. Em uma sociedade, é necessário adaptar-se a mudanças tecnológicas, proporcionando aprendizado autônomo com vistas a formação de cidadãos responsáveis e intervenientes na vida comunitária. Sendo assim, o aluno ganha espaço e passa a construir o seu próprio conhecimento.

Assim, a média alcançada nesse grupo foi de 6,69 pontos, o que é considerado um Nível Médio de aderência ao PBL para estas assertivas, havendo menor predominância de Metodologias Tradicionais de Ensino em favor de metodologias mais interativas, que prezem pela construção dos cinco princípios do PBL, conforme preconizou Ribeiro (2005), a interação social e a interação com a vida real, a motivação epistêmica, a metacognição e a construção do próprio conhecimento.

\subsubsection{Grupo 3: Nível Alto}

Neste grupo foram classificadas as assertivas que apresentaram médias superiores a 7,50 pontos, em um total de nove assertivas, o que por si já é um ponto favorável, ter $53 \%$ das atitudes dos professores associadas com nível alto de aderência às práticas do PBL

As duas primeiras assertivas ( $\mathrm{O}$ meu papel em sala de aula é baseado no docente facilitador, orientador e consultor profissional. Não havendo espaço para o papel de especialista ou autoridade formal) foram obtidos escores de 272 pontos com média de 7,56, e a assertiva (Busco a interação entre alunos e docentes de modo a fornecer feedback imediato sobre as atividades desenvolvidas com a finalidade de melhorar continuamente a didática de ensino). Também obteve um resultado positivo, o que confirma o resultado apresentado acima. Nesta questão, foi obtido um escore de 289 pontos e média de 7,89 .

Dentro desta mesma análise, o que significa uma mudança de postura dos professores na forma de agir e se comportar perante o processo de ensino, criando uma interação com os alunos A postura do professor em sala de aula como orientador, co-aprendiz e facilitador é um ponto pacificado na metodologia PBL (RIBEIRO, 2005) para a construção do conhecimento. Em relação a assertiva (Prefiro que os alunos trabalhem em pequenos grupos para a resolução de problemas permitindo a aquisição e aplicação de conhecimentos em contextos variados). Foi obtido um escore de 290 pontos e média de 8,05 , o que identifica a preferência dos docentes por trabalhar com um número menor de alunos por grupo. Os docentes enfatizam a manutenção de um ambiente onde exista apoio e colaboração. $\mathrm{Na}$ assertiva (A aprendizagem nas aulas ocorre em um ambiente de apoio e colaboração, sem incentivos ao individualismo ou competições). Foi obtido um escore de 292 e média de 8,11. Os docentes também prezam pelo trabalho em equipe, na assertiva (Prezo pelo trabalho em equipe, incluindo outros membros da escola/universidade em minhas atividades acadêmicas). Foi obtido um escore de 272 pontos e média de 7,56. As atitudes traduzidas por essas assertivas são especialmente importantes no universo das ciências contábeis, onde as exigências legais, sociais e profissionais do contador exigem do profissional competências que vão além do domínio do conhecimento técnicocientífico (SOARES; ARAÚJO, 2008).

GeCont, v. 4, n. 2, Floriano-PI, Jul-Dez. 2017. 
Em outra assertiva, foi abordada a forma de ensino com base em problemas da vida real (Busco ensinar baseando-me em problemas da vida real e delegando autoridade com responsabilidade aos alunos). Este questionamento está baseado no alicerce do PBL que traz a apresentação e solução de problemas como fundamental, houve um escore de 281 pontos e média de 7,81. Essa assertiva é corroborada por Martins (2013), a qual destaca que o ensino em contabilidade deve trabalhar as habilidades e atitudes exigidas do futuro profissional para atuar com competência no mercado de trabalho, o que certamente exige a discussão e a resolução de problemas reais durante o curso.

A valorização do conhecimento prévio e também o encorajamento de iniciativas obteve atenção especial por parte dos pesquisados. Foi atribuído um escore de 295 pontos e média de 8,19 . A orientação e incentivo aos alunos pela busca de conhecimento e recursos que facilitem o aprendizado e o desenvolvimento de habilidades na formação profissional, também obtiveram destaque. Em relação à questão sobre orientação, foi atribuído um escore de 316 pontos e média de 8,67 , já a questão que versava sobre incentivar os alunos na busca pelo o conhecimento, obteve um escore de 332 e média de 9,22, o maior dentre as assertivas desenvolvidas.

Foi possível considerar após análise deste grupo de assertivas que a média geral alcançada foi de 8,12 pontos, o que é considerado um Alto Nível de aderência ao PBL para estas assertivas, sendo predominantes as características inerentes a Aprendizagem Baseada em Problemas.

\section{CONSIDERAÇÕES FINAIS}

Considerando que os resultados foram divididos em três grupos: Nível Baixo, Nível Médio e Nível Alto de aproximação com a metodologia de ensino PBL, dentre as 17 assertivas formuladas, $53 \%$ foram classificadas no Nível Alto, 35\% como Nível Médio e $12 \%$ se destacaram como Nível Baixo.

No resultado geral, a média alcançada foi de 7,02 Pontos, aderência média das metodologias de ensino da contabilidade às técnicas do PBL. A partir da realização desta pesquisa, pode-se inferir que o processo de ensino vem sendo modificado e está quebrando alguns paradigmas na educação. Observe-se que os respondentes não foram questionados se detêm o conhecimento sobre o PBL, mas, do contrário, suas práticas foram analisadas à luz da metodologia. Com o que os resultados parecem de certa forma satisfatórios.

Ressalta-se nesse contexto que se faz necessário que as instituições de ensino trabalhem juntamente com o corpo docente no processo de construção do ensino-aprendizagem, de forma que os resultados apontem futuros profissionais aptos e seguros para enfrentar o mercado de trabalho.

Neste contexto, insere-se a importância da Aprendizagem Baseada em Problemas, como forma de quebrar o paradigma educacional, até hoje existente na sociedade. Em virtude da mudança do perfil estudantil e as diversas exigências no mundo dos negócios, as metodologias tradicionais estão cedendo espaço às novas metodologias a cada dia.

Sendo assim, as instituições de ensino precisam se conscientizar da necessidade desta mudança, adotar metodologias que complementem as tradicionais e estreitar a relação entre o meio acadêmico e o empresarial, de forma que o discente seja beneficiado por obter a destreza em resolver problemas de ordem prática e profissional e a empresa por receber no futuro, um profissional capaz de proporcionar o retorno que elas tanto almejam.

A introdução formalizada da metodologia PBL nos projetos pedagógicos dos cursos de graduação, pode significar uma quebra de paradigmas na educação superior. Além do despertar de novas habilidades, os alunos poderão participar ativamente da construção do próprio conhecimento. 
Concluiu-se que o ensino da contabilidade já possui algumas características do PBL, necessitando se consolidar e sistematizar nas IES pesquisadas, sendo que as principais deficiências são visualizadas na forma como os conteúdos são transmitidos, onde se percebe que os docentes ainda elaboram e ministram suas aulas com base em modelos tradicionais de ensino, priorizando a estrutura de palestras, e muitas vezes não permitindo que os alunos participem ativamente do processo avaliativo.

Como limitações da pesquisa destaca-se o tamanho e a região geográfica da amostra utilizada, e certamente a não possibilidade de generalização dos resultados para outras localidades. Das limitações são realizadas sugestões para pesquisas futuras, as quais podem analisar o contexto do PBL em outros cursos, instituições de ensino superior e outras regiões geográficas do Brasil, ou ainda a testagem de outras metodologias modernas de ensino, notadamente para a graduação no Brasil.

\section{REFERÊNCIAS}

ANDRADE, C. S. de. O ensino de Contabilidade Introdutória nas Universidades

ATHAYDE, M. Contabilidade Empreendedora. Prêmio Edgard Cornacchione Jr: disciplina mais inovadora do curso de graduação em Ciências Contábeis no Brasil no ano de 2014. XIV Congresso Usp de Controladoria e Contabilidade. São Paulo, 2014.

BARRETT, T.; Mac L.I.; Fallon, H. Handbook of Enquiry and Problem-based Learning: Irish case studies and international perspectives. CELT, 2005. Released under Creative Commons license. Attribution Non-Commercial 2.0. Some rights reserved. Recuperado em 15 outubro, 2014, de <http://www.nuigalway.ie/celt/pblbook>.

BARROWS, H. Kelson, A. (1993) Problem-based Learning: A Total Approach to Education. Illinois University Press.

BRASIL; Enem é porta de entrada para universidades e programas do governo. Recuperado em 25 fevereiro, 2015, de: <http://www.brasil.gov.br/educacao/2014/05/enem-eporta-de-entrada-para-universidades-e-programas-do-governo $>$.

DUARTE, S. V.; Furtado, M. S. V. Manual para elaboração de monografias e projetos de pesquisas. 3. ed. Montes Claros: Unimontes, 2002.

DUCH, B. Why PBL? Recuperado em 14 outubro, 2014, de <http://www.udel.edu/inst/whypbl.html> Acesso em 14/10/2014.

B. J; Groh, S. E; Allen, D. E. The power of problem-based learning: A practical

"how to" for teaching undergraduate courses in any discipline. Copyright 2001 by Stylus Publishing, LLC. United States of America.

FREZATTI, F. et al. Análise do desempenho de alunos na perspectiva do CHA em disciplina utilizando PBL: o que significa a síntese? XIV Congresso USP: Controladoria e Contabilidade. São Paulo: 2014.

KIESLER, S.; Sproull, L. S. Response effects in the electronic survey. Public Opinion Quarterly, Oxford, v. 50, n. 3, p. 402-413, Sept.1986.

MARION, J. C; Santos, M. C. O perfil do futuro profissional e sua responsabilidade social. Recuperado em 9 setembro, 2014, de

<http://www.crcpr.org.br/new/content/publicacao/revista/revista129/perfil.htm>.

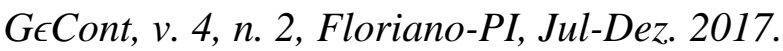


MARTINS, J. G. Aprendizagem baseada em problemas aplicada a ambiente virtual de aprendizagem. Tese de Doutorado. Programa de Pós-Graduação em Engenharia de Produção da Universidade Federal de Santa Catarina. Florianópolis: 2002.

MARTINS, D. B. Avaliação de habilidades e de atitudes em abordagem de problembased learning no ensino de controle gerencial. Dissertação de Mestrado. Programa de Mestrado em Contabilidade da Universidade Federal do Paraná. Curitiba: 2013.

D. B.; Espejo, M. M. S. B. Problem-Based Learning no Ensino de Contabilidade. São Paulo: Atlas, 2015.

D. B.; Espejo, M. M. S. B.; Frezatti, F. Problem-Based Learning no Ensino de Contabilidade Gerencial: Relato de uma Experiência Brasileira.REPeC - Revista de Educação e Pesquisa em Contabilidade. Brasília, v.9, n.4, art. 5, p. 430-452, out./dez. 2015

MASETTO. M. Aborda desafios da docência no ensino superior. Recuperado em 15 outubro, 2014, de: <http://www.unicuritiba.edu.br/noticias/prof-marcos-masetto-abordadesafios-da-docencia-no-ensino-superior>. Acesso em: 15/10/2014.

OLIVEIRA, T. M. V. de. Escalas de mensuração de atitudes: Thurstone, Osgood, Stapel, Likert, Guttman, Alpert. Administração On Line, São Paulo, v. 2, n. 2, abr.jun. 2001. Recuperado em 2 dezembro, 2014, de: 〈http://www.fecap.br/adm_online/art22/tania.htm>.

RIBEIRO, L. R. C. A Aprendizagem Baseada em Problemas (PBL): uma implementação na educação em engenharia na voz dos atores. Tese de doutorado. Programa de PósGraduação. São Carlos: UFSCar, 2005. 209 p.

Ribeiro, L. R. C. Aprendizagem baseada em problemas (PBL): uma experiência no ensino superior. São Carlos: EdUFSCar, 2008

SAMFORD UNIVERSITY. Problem-Based Learning. Recuperado em 15 outubro, 2014, de: <http://www.samford.edu/ctls/archives.aspx ?id=2147484112>.

SAMPIERI, R. H.; COLLADO, C. F.; Lucio P. B. Metodologia de pesquisa. 3. ed. São Paulo: McGraw-Hill, 2006.

SCHWARTZ, P. MENNIN, S; WEBB, G. Problem-Based Learning: Case studies, experience and practice. First published in 2001 by Routledge. London and New York.

SILVA FILHO, M. et. al. Como preparar os professores brasileiros da educação básica para a aprendizagem baseada em problemas? PBL 2010. Congresso Internacional. São Paulo, Brasil, 8 - 12 fevereiro de 2010.

SOARES, M. A; ARAÚJO, A. M. P. (2008). Aderência ao método de ensino ProblemBased Learning (PBL) no curso de Ciências Contábeis: um estudo empírico. In $2^{\circ}$ Congresso ANPCONT. Salvador-BA. Recuperado em 23 novembro, 2014, de: $<$ https://www.furb.br/especiais/download/879756-215326/epc\%20045\%20\%20index3.php.pdf $>$.

STANLEY, T. A; MARSDEN, S. J. Problem-based learning does accounting education need it? Journal Accounting Education, 30(3/4), pp. 267-289. Austrália: 2012.

WOLFS, J. L. 2000. Análise das práticas educativas que visam à participação do aluno na avaliação diagnóstica, na condução e na regulação de suas aprendizagens. In: J. Grégoire et al. (org.), Avaliando as aprendizagens: os aportes da psicologia cognitiva. Porto Alegre, Editora Artes Médicas Sul, p. 169-179. 
WOODS, D. Problem-based Learning, especially in the context of large classes. MacMaster University, Department of Chemical Engineering Web Site. Disponível em:

<http://chemeng.macmaster.ca/pbl/pbl.htm>. Acesso em: 31 ago. 2000.

D. Problem-Based Learning. Recuperado em 14 outubro, 2014, de:

<http://chemeng.mcmaster.ca/problem-based-learnig>. 
APÊNDICE. Questões inerentes a aderência ao PBL no processo de ensino dos docentes pesquisados

\begin{tabular}{|c|c|c|c|c|c|c|}
\hline Assertiva & $\mathbf{N}$ & Escore & Média & Mediana & Moda & $\begin{array}{l}\text { Desvio } \\
\text { Padrão }\end{array}$ \\
\hline No processo avaliativo atuo como único avaliador. & 36 & 103 & 2,861 & 2 & 0 & 2,800 \\
\hline Os conteúdos nas disciplinas em que leciono, são conduzidos em formato de palestras. & 36 & 164 & 4,556 & 4 & 7 & 2,580 \\
\hline Dou abertura para que os alunos avaliem suas próprias contribuições, além de outros membros e do grupo como um todo. & 36 & 204 & 5,667 & 6 & 0 & 3,251 \\
\hline Nas minhas aulas, os alunos se responsabilizam por sua própria aprendizagem e buscam a criação de parcerias entre colegas e professores & 36 & 223 & 6,194 & 6,5 & 7 & 1,864 \\
\hline $\begin{array}{l}\text { A estrutura escolar na qual estou inserido (a) é flexível e oferece apoio aos docentes. Sou encorajado (a) a mudar o panorama instrucional e } \\
\text { avaliativo mediante novos instrumentos de avaliação. }\end{array}$ & 36 & 224 & 6,222 & 7 & 8 & 2,727 \\
\hline $\begin{array}{l}\text { Busco "desencorajar" a resposta correta, única e ajudo os alunos a delinearem questões, equacionarem problemas, explorarem alternativas } \\
\text { e tomarem decisões eficazes. }\end{array}$ & 36 & 241 & 6,694 & 7,5 & 8 & 2,734 \\
\hline $\begin{array}{l}\text { Os alunos identificam, analisam e resolvem problemas utilizando conhecimentos prévios e experiências anteriores, ao invés de simplesmente } \\
\text { relembrá-los. }\end{array}$ & 36 & 256 & 7,111 & 7 & 7 & 2,067 \\
\hline $\begin{array}{l}\text { Apresento o conteúdo utilizando problemas "não estruturados" que proporcionam o desenvolvimento de habilidades. Não incentivando a } \\
\text { memorização de informações em um conteúdo especifico. }\end{array}$ & 36 & 261 & 7,250 & 7,5 & 7 & 1,918 \\
\hline $\begin{array}{l}\text { O meu papel em sala de aula é baseado no docente facilitador, orientador e consultor profissional. Não havendo espaço para o papel de } \\
\text { especialista ou autoridade formal. }\end{array}$ & 36 & 272 & 7,556 & 8 & 8 & 1,904 \\
\hline Prezo pelo trabalho em equipe, incluindo outros membros da escola/universidade em minhas atividades acadêmicas. & 36 & 272 & 7,556 & 8 & 8 & 1,858 \\
\hline Busco ensinar baseando-me em problemas da vida real e delegando autoridade com responsabilidade aos alunos. & 36 & 281 & 7,806 & 8 & 7 & 1,600 \\
\hline $\begin{array}{l}\text { Busco a interação entre alunos e docente de modo a fornecer feedback imediato sobre as atividades desenvolvidas com a finalidade de } \\
\text { melhorar continuamente a didática de ensino. }\end{array}$ & 36 & 284 & 7,889 & 8 & 9 & 1,939 \\
\hline $\begin{array}{l}\text { Prefiro que os alunos trabalhem em pequenos grupos para a resolução de problemas, permitindo a aquisição e aplicação de conhecimentos } \\
\text { em contextos variados. }\end{array}$ & 36 & 290 & 8,056 & 8 & 8 & 1,739 \\
\hline A aprendizagem nas aulas ocorre em um ambiente de apoio e colaboração, sem incentivos ao individualismo ou competições. & 36 & 292 & 8,111 & 9 & 9 & 1,753 \\
\hline Valorizo o conhecimento prévio do aluno, busco encorajar a iniciativa e delegar autoridade a eles com responsabilidade. & 36 & 295 & 8,194 & 8 & 10 & 1,653 \\
\hline Procuro orientar os alunos para que eles encontrem recursos e informações úteis em seu processo de aprendizado. & 36 & 312 & 8,667 & 9 & 10 & 1,352 \\
\hline Sempre incentivo os alunos na busca pelo conhecimento e desenvolvimento de habilidades relevantes para a sua futura prática profissional. & 36 & 332 & 9,222 & 10 & 10 & 1,124 \\
\hline
\end{tabular}

Fonte: Elaborado pelos autores.

GєCont, v. 4, n. 2, Floriano-PI, Jul-Dez. 2017. 